\title{
Redox Status Is Critical for Stemness in Skin Equivalents
}

\author{
Hye-Ryung Choi, Youn-A Kang, Jung-Won Shin, Jung-Im Na, \\ Chang-Hun Huh, and Kyoung-Chan Park
}

Department of Dermatology, Bundang Seoul National University Hospital, Seoul National University College of Medicine, 166 Gumi-ro, Bundang-gu, Seongnam-si 463-707, Republic of Korea

Correspondence should be addressed to Kyoung-Chan Park, gcpark@snu.ac.kr

Received 1 June 2012; Accepted 30 July 2012

Academic Editor: Jing Yi

Copyright (๑) 2012 Hye-Ryung Choi et al. This is an open access article distributed under the Creative Commons Attribution License, which permits unrestricted use, distribution, and reproduction in any medium, provided the original work is properly cited.

The skin is constantly exposed to environmental oxidative stress. Skin equivalent (SE) models are three-dimensional systems in which cell-cell or cell-matrix interactions can be investigated. In this study, the effects of vitamin $\mathrm{C}$ or plant extracts with high antioxidant activities were tested. There was no significant difference in the epidermal thickness, but the basal cells became cuboidal when vitamin $\mathrm{C}$ or plant extracts were supplemented. Furthermore, immunohistochemical staining showed linear and intense staining of $\alpha 6$ and $\beta 1$ integrin along the basement membrane in vitamin $\mathrm{C}$ or plant extract treated models. The p63 and PCNA were also stained. Results showed that the number of p63 and PCNA positive cells was higher in the vitamin C or plant extract treated models than in the control SEs. Although the relationship between oxidative stress and stem cells is not known, our results suggest that redox status affects the stemness and the proliferative potential of epidermal basal cells by modulating microenvironment to epidermal basal stem cells.

\section{Introduction}

Most in vitro studies have been done in two-dimensional monocultures, while accumulating evidences suggest that cells behave differently when they were grown within a threedimensional (3D) extracellular matrix and also interact with other cells [1]. The development of 3D skin equivalent (SE) models has enabled the field to investigate cell-matrix and cell-cell interactions between different cell types [1]. So far, in vitro evaluation of skin sensitivity will be a most common application of SE models [2]. Furthermore, SE models can be used for an efficacy testing to prove antiageing activity [3] or hypopigmenting effects [4]. However, SEs will be more useful experimental models in many aspects of biology. Vitamin C is an important low-molecular weight antioxidant molecule that, in addition to stimulating collagen synthesis, also appears crucial for the healing process and wound repair [5]. Furthermore, it has been reported that vitamin $\mathrm{C}$ promotes formation of the epidermal barrier [6], and we also reported that vitamin $\mathrm{C}$ affects epidermalization in reconstructed human epidermis [7]. Recently, it is reported that epidermal side population with stem cell-like characteristics exhibited less mitochondrial area, fewer peroxisomes, and produced lower levels of reactive oxygen species (ROS) than more differentiated keratinocytes [8]. These findings suggest that redox status may be an important regulator of epidermalization. Then, it will be interesting to examine various antioxidants for these effects. Ganoderma lucidum (G. lucidum), a highly nutritional and medicinal mushroom, is known to have strong antioxidant activities [9]. Rhodiola sachalinensis ( $R$. sachalinensis), which had been widely used as a traditional medicine, is known to have active compounds such as catechin, chlorogenic acid, p-Coumaric acid, and ptyrosol [10]. In this study, the effects of vitamin $C$ and plants extracts from G. lucidum and $R$. sachalinensis were studied in 3D SE models in terms of basement membrane formation and stem cell markers.

\section{Material and Methods}

2.1. Extraction Procedure. To obtain the extracts, the plants were thoroughly dried and ground into powder, and then 
$50 \%$ ethanol was used to extract the soluble components at room temperature for $24 \mathrm{hrs}$. The extracts were then filtered through Whatman filter paper (Whatman Ltd, Maidstone, England) and concentrated as a stock solution $(100 \mathrm{mg} / \mathrm{mL})$.

2.2. DPPH Radical Scavenging Assay. A sample of each stock solution $(2 \mu \mathrm{L}, 100 \mathrm{x})$ was added to $80 \mu \mathrm{L}$ of $0.25 \mathrm{mM} 1,1-$ diphenyl-2-picrylhydrazyl (DPPH, Sigma-Aldrich, St. Louis, $\mathrm{MO}$ ) and $118 \mu \mathrm{L}$ of $70 \%$ ethanol to give a final DPPH concentration of $0.1 \mathrm{mM}$. Next, the mixture was vigorously shaken and then left to stand for $10 \mathrm{~min}$ in the dark. The absorbance at $517 \mathrm{~nm}$ was then measured using an ELISA reader (TECAN, Salzburg, Austria) [11].

2.3. Primary Culture of Keratinocytes and Fibroblasts. Normal human keratinocytes and fibroblasts were isolated from human foreskins obtained during circumcisions. All samples were obtained with informed consent. Keratinocytes were cultured in keratinocyte growth medium (KGM, Clonetics, San Diego, CA), and fibroblasts were cultured in Dulbecco's modified Eagle's medium (DMEM, LM001-05, WelGENE, Daegu, Republic of Korea) supplemented with 10\% fetal bovine serum (FBS, Thermo Scientific HyClone, Logan, UT).

2.4. MTT Assay for Cell Cytotoxicity. Cells $\left(4 \times 10^{4}\right.$ cells/well $)$ were seeded into 24 -well plates. After serum starvation for $24 \mathrm{hrs}$, the cells were incubated with test samples for $24 \mathrm{hrs}$ at $37^{\circ} \mathrm{C}$ under $5 \% \mathrm{CO}_{2}$. MTT (Sigma-Aldrich) solution $(100 \mu \mathrm{L}$ of $5 \mathrm{mg} / \mathrm{mL}$ ) was added, and the plates were incubated for an additional $4 \mathrm{hrs}$. The supernatant was removed, and the formazan crystals were dissolved in dimethylsulfoxide $(1 \mathrm{~mL}$, Sigma-Aldrich). Then, the optical density was determined at $540 \mathrm{~nm}$ using an ELISA reader (TECAN) [12].

2.5. Reconstruction of Skin Equivalents. SEs were constructed following our previous method [12]. Briefly, dermal substitutes were prepared according to the reported method with some modifications [13]. Type I collagen was extracted from the tendons of rat-tails. Dermal substitutes were then made by mixing eight volumes of type I collagen with one volume of $10 \mathrm{x}$ concentrated DMEM and one volume of neutralization buffer $\left(0.05 \mathrm{~N} \mathrm{NaOH}, 0.26 \mathrm{mM} \mathrm{NaHCO}_{3}\right.$, and $200 \mathrm{mM}$ HEPES) and then adding $5 \times 10^{5}$ fibroblasts. After gelling in a $30 \mathrm{~mm}$ polycarbonate filter chamber $(3.0 \mu \mathrm{m}$ Millicell; Millipore, Bedford, MA), human keratinocytes $(1 \times$ $10^{6}$ cells) were then seeded onto the dermal substitute. After 1 day in a submerged state, they were cultured at the airliquid interface for 12 days. The growth medium consisted of DMEM and Ham's nutrient mixture F12 at a ratio of $3: 1$, supplemented with $5 \% \mathrm{FBS}, 0.4 \mu \mathrm{g} / \mathrm{mL}$ hydrocortisone, $1 \mu \mathrm{M}$ isoproterenol, $25 \mu \mathrm{g} / \mathrm{mL}$ ascorbic acid, and $5 \mu \mathrm{g} / \mathrm{mL}$ insulin. A low concentration of EGF $(1 \mathrm{ng} / \mathrm{mL}$, Invitrogen Co., Carlsbad, CA) was also added during the submerged culture, and a higher concentration of EGF $(10 \mathrm{ng} / \mathrm{mL})$ was added during the air-liquid interface culture. The medium was changed three times per week, and all experiments were repeated at least twice under the same conditions. During the air exposure period, samples were added.
2.6. Histology and Immunohistochemistry. At the end of the growth period, the SEs were fixed with Carnoy's fixative and embedded in paraffin. Immunohistochemical staining was performed on deparaffinized sections using the avidinbiotin-peroxidase complex technique (DAKO, Carpinteria, CA). Antibodies against integrin $\alpha 6$ (\#sc-6597), integrin $\beta 1$ (\#sc-9970), and p63 (4A4, \#sc-8431) were obtained from Santa Cruz Biotechnology, Inc (Santa Cruz, CA). Antibody against PCNA (proliferating cell nuclear antigen, \#M0879) was obtained from DAKO (Glostrup, Denmark). Results of immunohistochemistry were analyzed quantitatively using MetaMorph Offline version 7.7.0.0 image analysis software (Molecular Devices, Downingtown, PA). The statistical analysis was done using Microsoft Office Excel 2007's TTEST function.

\section{Results}

3.1. Antioxidant Activity of Plant Extracts. G. lucidum and $R$. sachalinensis, which are frequently used in herbal medicine, were chosen because of their well-known antioxidant activities $[9,10,14]$. After being extracted with 50\% ethanol, the concentrated extracts $(100 \mathrm{x})$ were prepared, and their scavenging effects on DPPH radicals were examined. Compared to vitamin C, the extracts from G. lucidum and $R$. sachalinensis showed relatively weak antioxidant activity at low concentrations $(10 \mu \mathrm{g} / \mathrm{mL})$ but good antioxidant activities at high concentrations $(100 \mu \mathrm{g} / \mathrm{mL})$ (Figure 1).

3.2. Cytotoxicity of Plant Extracts. The cytotoxicity of the plant extracts was analyzed using an MTT assay. Cultured normal human keratinocytes were incubated with increasing concentrations of plant extract up to $100 \mathrm{~g} / \mathrm{mL}$ (Figure 2). The results showed that extracts from G. lucidum and $R$. sachalinensis were not toxic at any of the concentrations tested. Interestingly, high concentrations of extract from $R$. sachalinensis slightly increased the proliferation of normal human keratinocytes (Figure 2).

3.3. Histology of Normal Skin and SEs. Characteristic multilayering and stratification of the epidermis were observed in all of the SE models. There was no significant difference in the thickness of the epidermis. However, the basal cells became cuboidal when vitamin $\mathrm{C}$ or plant extracts were added (Figures 3(c), 3(d), 3(e), and inserts).

3.4. Immunohistochemical Staining for Integrins. Integrin $\alpha 6$ is a marker of extracellular adhesion receptors that is distributed along the dermal epidermal junction and indicates the existence of hemidesmosomes [15]. Integrin $\beta 1$, which is expressed throughout the basal cell membrane, plays a role in cell-matrix and cell-cell interactions [16]. Immunohistochemical staining revealed that linear and intense staining of $\alpha 6$ and $\beta 1$ integrin was observed along the basement membrane in vitamin $\mathrm{C}$ or plant extract treated models (Figure 4). 


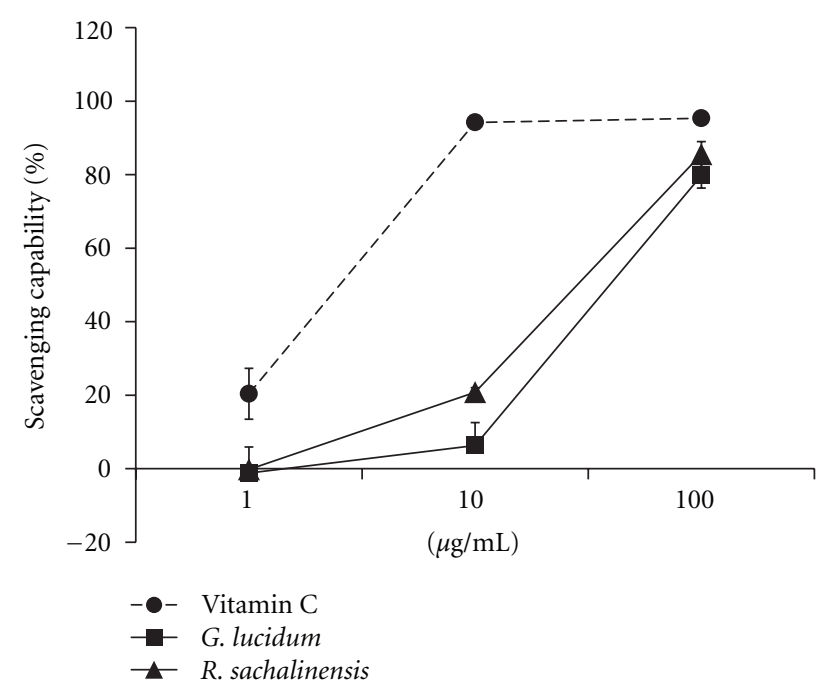

FIgURE 1: Scavenging effects of antioxidants for DPPH. Scavenging effects were assessed as described in Materials and Methods section. Data shown are the means \pm SD of three independent experiments. Vit. C:, vitamin C; G. l:, G. lucidum; R. s:, R. Sachalinensis.

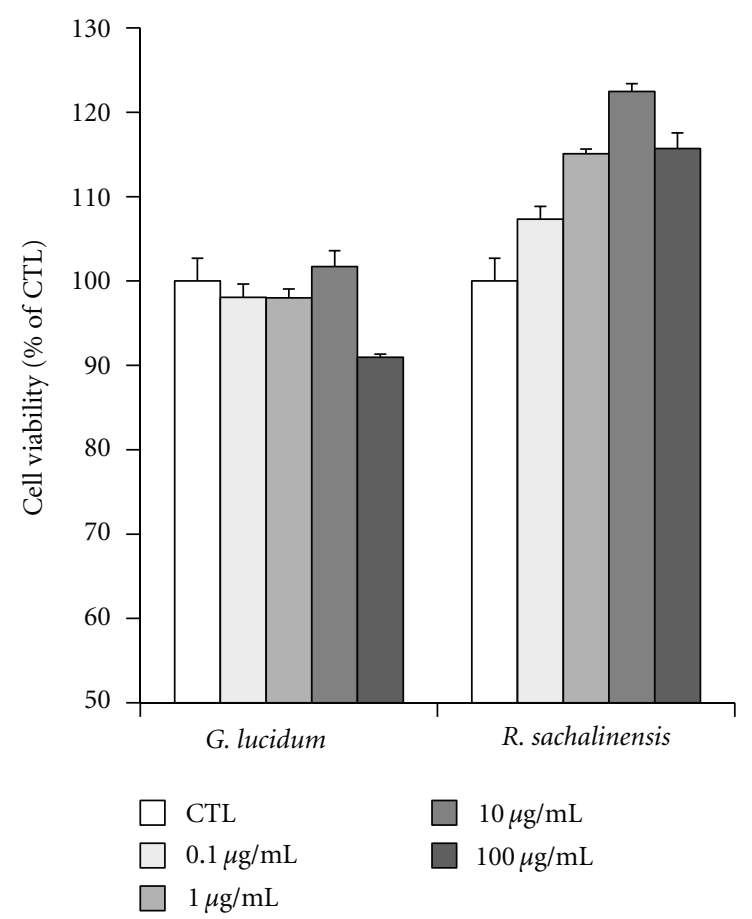

Figure 2: Effects of antioxidants on keratinocyte viability. Cells were serum-starved for 24 hrs and then treated with antioxidant plant extracts at $0.1-100 \mu \mathrm{g} / \mathrm{mL}$ for $24 \mathrm{hrs}$ in serum-free media. Cell viabilities were determined using MTT assays. Each determination was made in triplicate, and the data shown are the means \pm SD. G. l: G. lucidum; R. s: R. sachalinensis.

3.5. Immunohistochemical Staining for p63 and PCNA. The p63 is a potential stem cell marker that belongs to a family that includes two structurally related proteins, p53 and p73 [17]. PCNA is known to be present throughout the cell cycle in proliferating cells [18]. Immunohistochemical staining for p63 and PCNA was performed, and the number of p63 and PCNA positive cells was counted in randomly selected 5 different high-power fields. Results showed that the number of p63 and PCNA positive cells was generally higher in the vitamin $\mathrm{C}$ or plant extract treated models than in the control SEs. However, the number of PCNA positive cells was not increased in low concentration of plant extract treated models.

\section{Discussion}

The skin is constantly exposed to exogenous sources of oxidative stress, including ultraviolet (UV) radiation, chemical oxidants, and aerobic microorganisms. Because the skin must provide the first line of defense against environmental 
(a) Normal skin

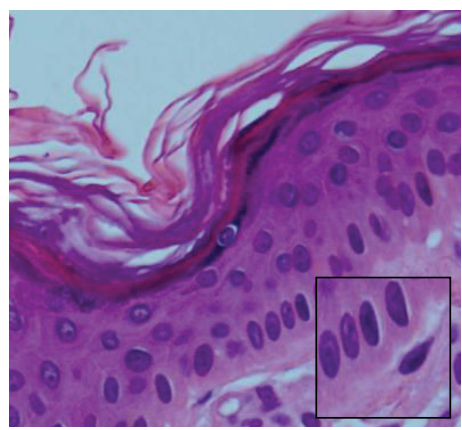

(c) Vitamin C
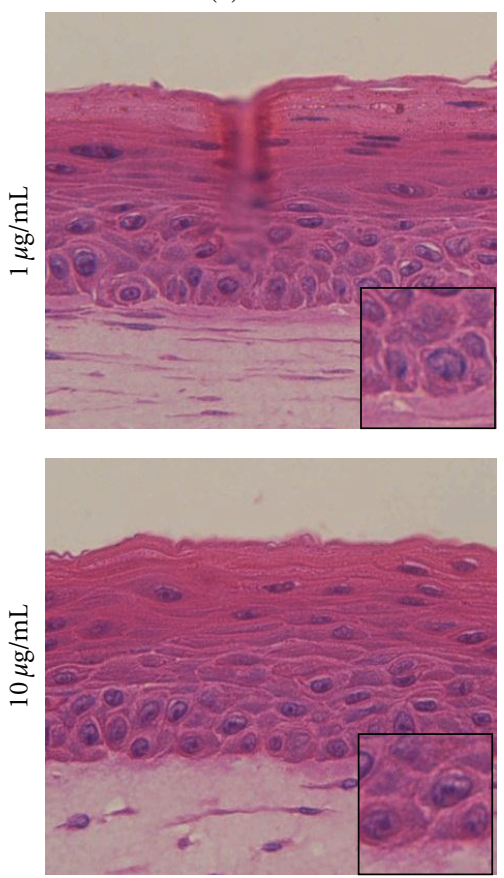

(b) CTL

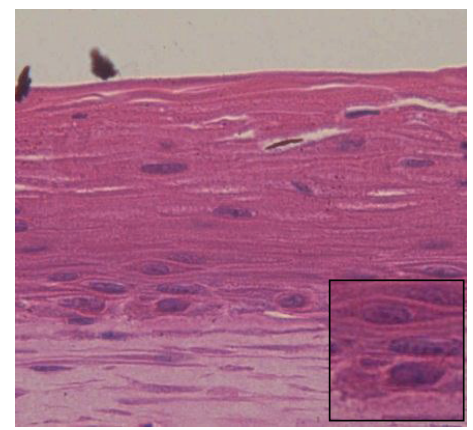

(d) G. lucidum
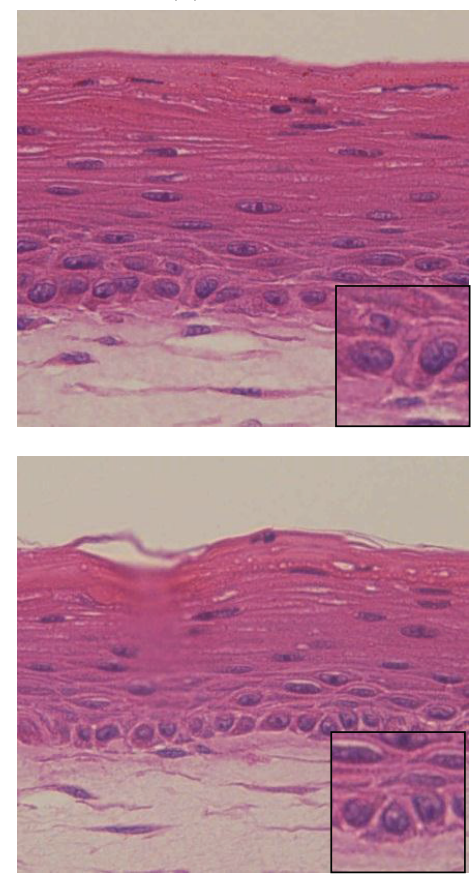

(e) R. sachalinensis
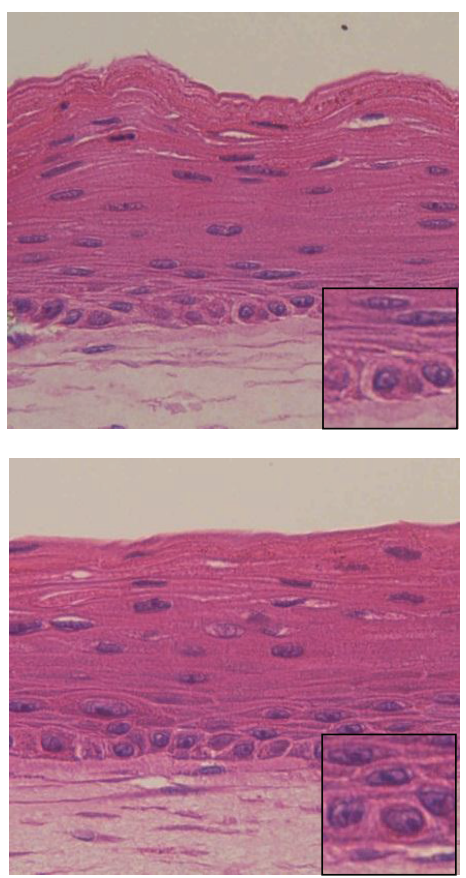

Figure 3: Histologic findings of normal skin and SEs. SEs were constructed and incubated in the presence of vitamin C, G. lucidum, or R. sachalinensis at a concentration of 1 or $10 \mu \mathrm{g} / \mathrm{mL}$. Sections of SEs were hematoxylin/eosin stained. (a) normal skin, (b) control SE, (c) SE treated with vitamin C, (d) SE treated with G. l, (e) SE treated with R. s.

free radical stress, it has developed a complex antioxidant network that includes enzymatic and nonenzymatic components [19]. Thus, various antioxidants are used to make skin care products in order to provide protective effects against environmental free radical. It is well known that there are diverse actions of antioxidant in normal physiology and also in pathologic conditions [20]. Then, various aspects of research are absolutely needed to understand the role of antioxidants.

SE models provide an investigative system in which cell-cell or cell-matrix interactions can be tested [13]. In this study, the effects of vitamin $\mathrm{C}$ or plant extracts with high antioxidant activities were investigated using 3D SE models. First of all, histologic findings were compared. Although the thickness of the epidermis was similar in all of the models tested in this study, the basal layer appeared to be more compact in the models that were treated with vitamin $\mathrm{C}$ or plant extracts (Figure 3). In normal skin, basal cells appear cuboidal in shape with their long axes aligned perpendicular to the dermoepidermal junction (Figure 3(a), insert). Furthermore, cuboidal keratinocytes flatten as differentiation progresses (Figure 3(a)). Our study also showed that the basal cell looked cuboidal when vitamin $\mathrm{C}$ or plant extracts were added. Therefore, it can be said that cuboid-shaped basal cells are considered to be epidermal basal cells with higher proliferative potential. Taken together, the results of this study suggest that antioxidants are an important regulator in the maintenance of the proliferative potential of epidermal basal cells.

In order to analyze the mechanism, expression of integrins was studied. Integrin $\alpha 6$ is distributed along the dermal epidermal junction [15]. Integrin $\beta 1$ is expressed throughout the basal cell membrane [21, 22]. Our results showed that there was increased expression of $\alpha 6$ and $\beta 1$ integrin 


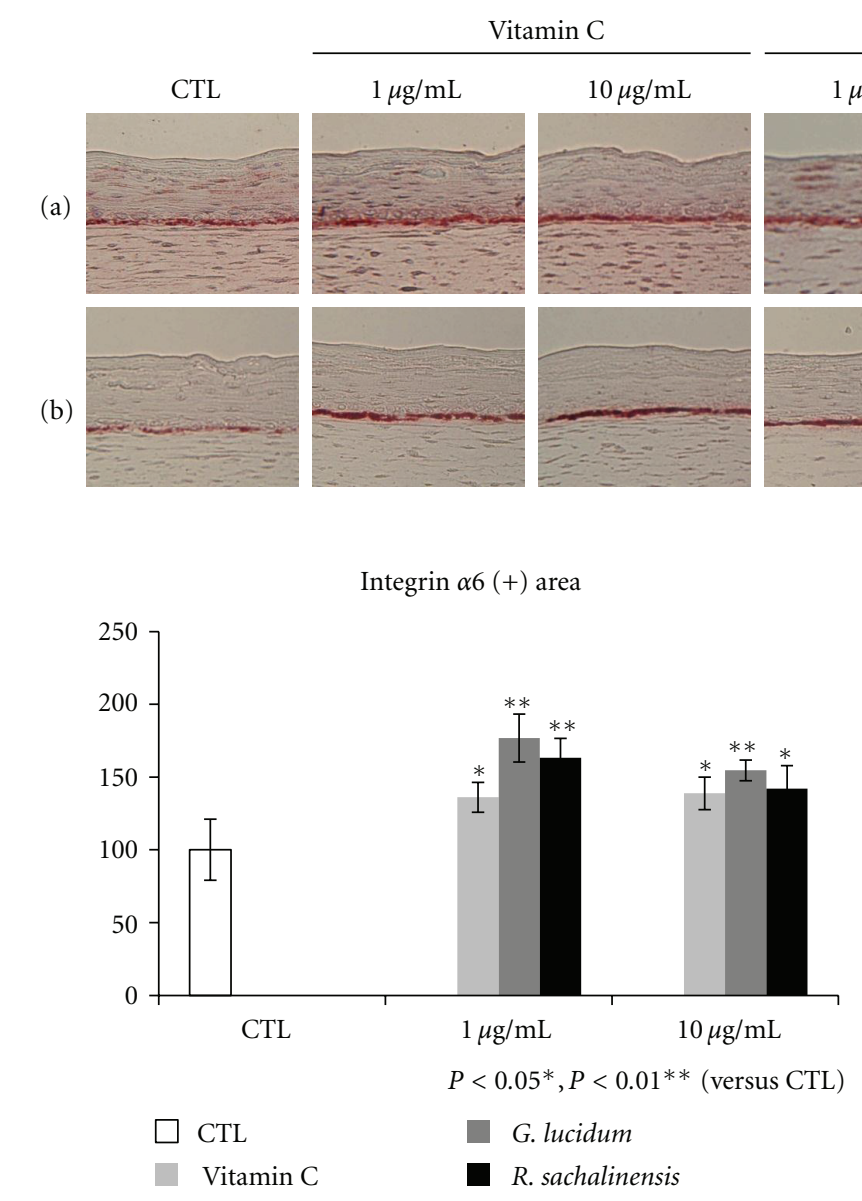

(a)

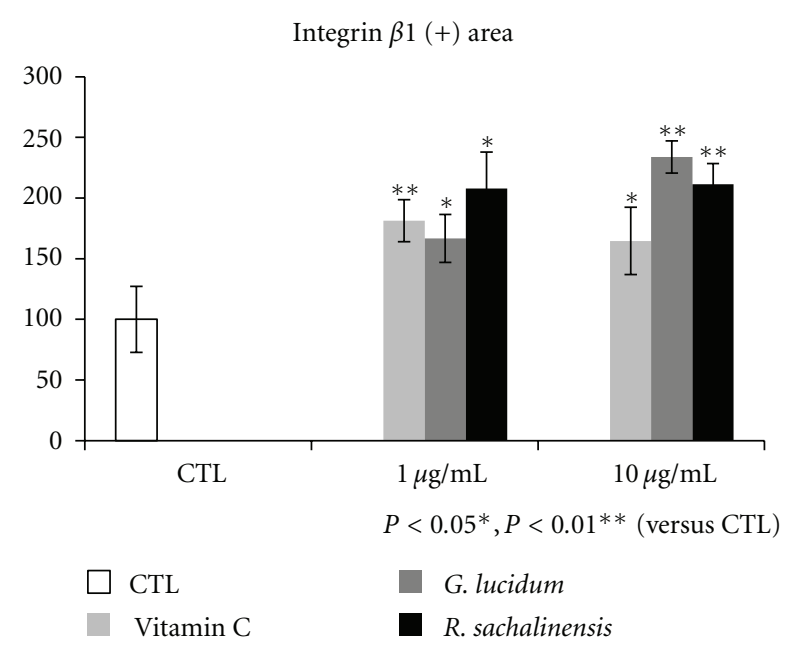

(b)

FIgURE 4: Immunohistochemical staining for integrins. The SEs were constructed and incubated in the presence of vitamin C (Vit. C), G. lucidum, or R. sachalinensis at 1 or $10 \mu \mathrm{g} / \mathrm{mL}$. Sections of SEs were stained for integrin $\alpha 6$ (a) or integrin $\beta 1$ (b). Intensity of both integrins was significantly increased by addition of Vit. C or plant extracts.

along the basement membrane when SEs were treated with vitamin C or plant extracts. It is reported that integrin expression is reduced in standard SE models compared to normal skin [7]. Thus, our findings suggest that vitamin $\mathrm{C}$ or these plant extracts improved the microenvironment of epidermal basal cells by modulating integrin expression. Aging is usually defined as a phenomenon which exhibits a deviation from the normal program of extracellular matrix biosynthesis [23]. In the skin, cell-ECM interactions also influence normal homeostasis, aging, wound healing, and diseases [24]. Because basement membrane is an epidermal ECM, changes of integrin expression can affect the fate of epidermal stem cells. The p63 is known as a putative stem cell marker of skin [17]. Our results also revealed that vitamin $C$ or plant extracts increased the number of p63 positive cells compared to control model (Figure 5(a)). These findings showed that vitamin $\mathrm{C}$ or plant extracts promotes the survival of epidermal basal cells in SEs. Recently, it has also been reported that p63 regulates an adhesion program and cell survival in epithelial cells [25]. In order to found the relationship between the stemness and proliferative potential, immunohistochemical staining for PCNA was performed. The number of PCNA positive cells increased by the addition of vitamin $\mathrm{C}$ or high concentrations of plant extracts (Figure 5(b)). These results showed that the number of proliferating cells is increased by the addition of vitamin C or plant extracts. In summary, it can be said that vitamin $\mathrm{C}$ or plant extracts increased the stemness and the proliferative potential of epidermal basal cells. Although the relationship between oxidative stress and stem cells is not known, recent publication showed that epidermal side population with stem cell-like characteristics produced lower levels of ROS than more differentiated cells [8]. In addition, our results showed that addition of vitamin $\mathrm{C}$ or plant extracts increased the stemness of epidermal basal cells. Thus, these findings suggest that antioxidant increased the stemness and the proliferative potential of epidermal basal cells by providing favorable microenvironment. Although the specific component of G. lucidum or $R$. sachalinensis can show these effects, our results provide evidence that redox status affects stemness and proliferative potential of epidermal basal stem cells, but further study is necessary 


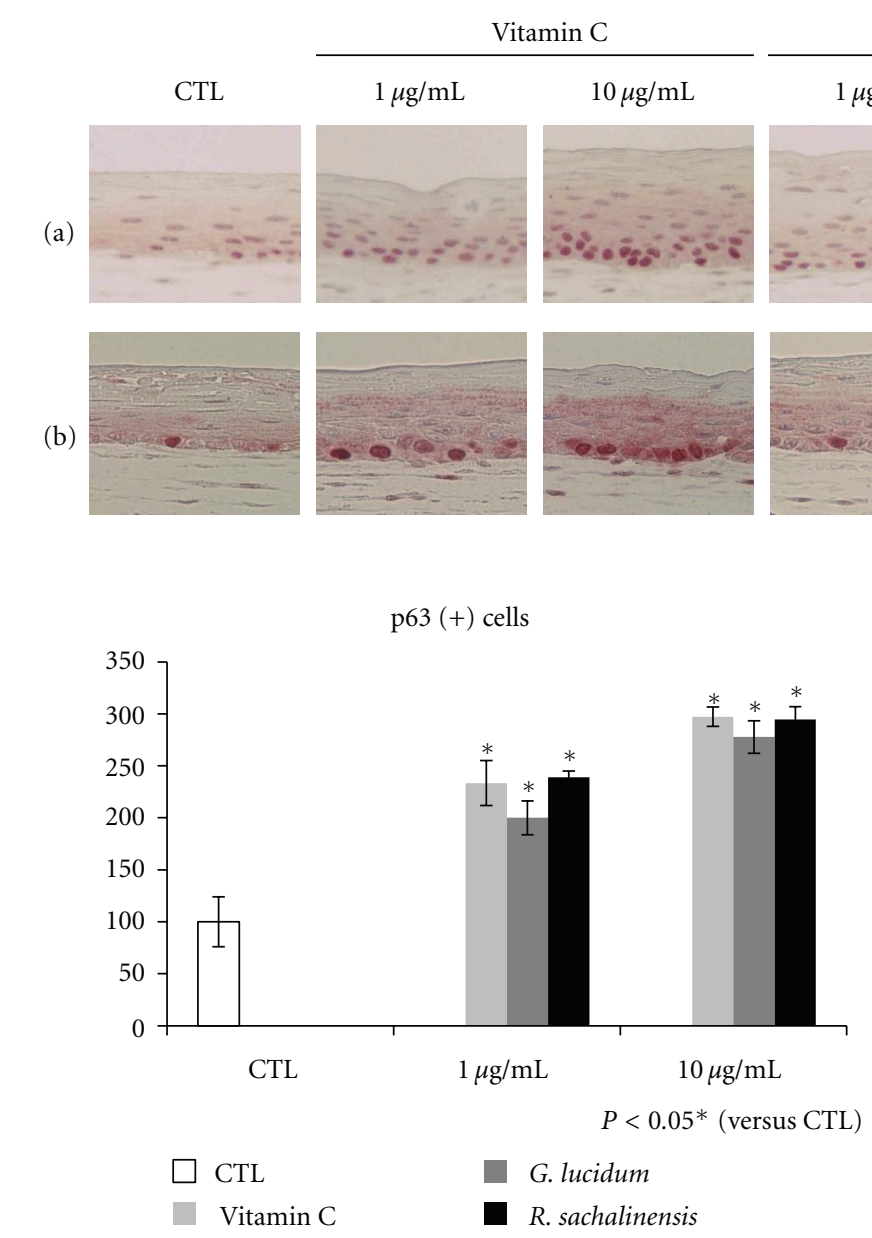

(a)

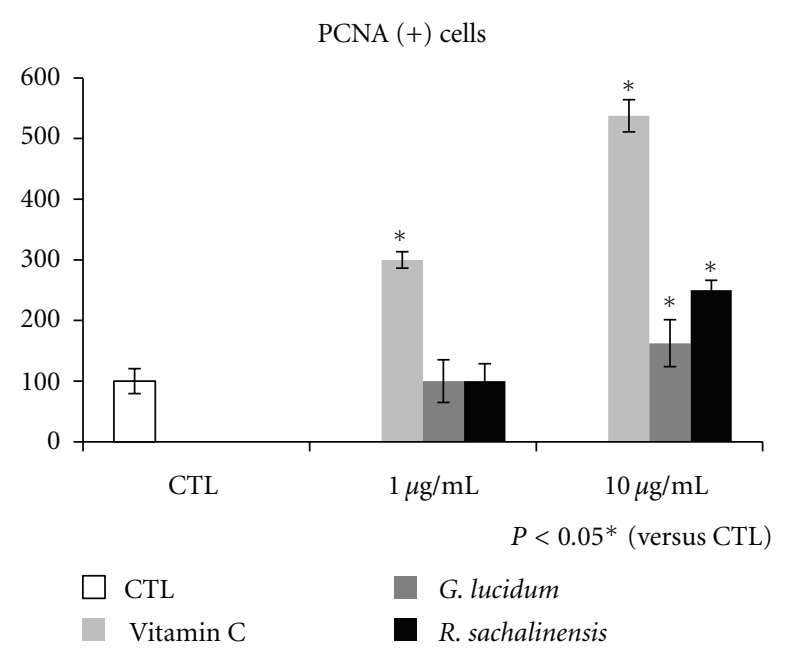

(b)

FIGURE 5: Immunohistochemical staining for p63 and PCNA. The SEs were constructed and incubated in the presence of vitamin C (Vit.C), G. lucidum, or R. sachalinensis at 1 or $10 \mu \mathrm{g} / \mathrm{mL}$. Sections of SEs were stained for p63 (a) or PCNA (b).

to explore the molecular mechanism of vitamin $\mathrm{C}$ or plant extract.

\section{Acknowledgments}

This study was supported by a grant of the Korea Healthcare technology R\&D Project, Ministry of Health \& Welfare, Republic of Korea (Grant no. A100179, A103017).

\section{References}

[1] L. Li, M. Fukunaga-Kalabis, and M. Herlyn, "The threedimensional human skin reconstruct model: a tool to study normal skin and melanoma progression," Journal of Visualized Experiments, no. 54, Article ID e2937, 2011.

[2] M. Nagasawa, H. Hayashi, and T. Nakayoshi, "In vitro evaluation of skin sensitivity of povidone-iodine and other antiseptics using a three-dimensional human skin model," Dermatology, vol. 204, supplement 1, pp. 109-113, 2002.

[3] V. Frei, E. Perrier, I. Orly, A. Huc, C. Augustin, and O. Damour, "Activation of fibroblast metabolism in a dermal and skin equivalent model: a screening test for activity of peptides,"
International Journal of Cosmetic Science, vol. 20, no. 3, pp. 159-173, 1998.

[4] Z. Wang, X. Li, Z. Yang, X. He, J. Tu, and T. V. Zhang, "Effects of aloesin on melanogenesis in pigmented skin equivalents," International Journal of Cosmetic Science, vol. 30, no. 2, pp. 121-130, 2008.

[5] M. V. Catani, I. Savini, A. Rossi, G. Melino, and L. Avigliano, "Biological role of vitamin C in keratinocytes," Nutrition Reviews, vol. 63, no. 3, pp. 81-90, 2005.

[6] S. T. Boyce, A. P. Supp, V. B. Swope, and G. D. Warden, "Vitamin C regulates keratinocyte viability, epidermal barrier, and basement membrane In Vitro, and reduces wound contraction after grafting of cultured skin substitutes," Journal of Investigative Dermatology, vol. 118, no. 4, pp. 565-572, 2002.

[7] S. Wha Kim, I. W. Lee, H. J. Cho et al., "Fibroblasts and ascorbate regulate epidermalization in reconstructed human epidermis," Journal of Dermatological Science, vol. 30, no. 3, pp. 215-223, 2002.

[8] W. J. Carr, R. E. Oberley-Deegan, Y. Zhang, C. C. Oberley, L. W. Oberley, and M. Dunnwald, "Antioxidant proteins and reactive oxygen species are decreased in a murine epidermal side population with stem cell-like characteristics," Histochemistry and Cell Biology, vol. 135, no. 3, pp. 293-304, 2011. 
[9] T. P. Smina, J. Mathew, K. K. Janardhanan, and T. P. A. Devasagayam, "Antioxidant activity and toxicity profile of total triterpenes isolated from Ganoderma lucidum (Fr.) P. Karst occurring in South India," Environmental Toxicology and Pharmacology, vol. 32, no. 3, pp. 438-446, 2011.

[10] S. H. Park, D. S. Kim, S. H. Park, J. W. Shin, S. W. Youn, and K. C. Park, "Inhibitory effect of p-coumaric acid by Rhodiola sachalinensis on melanin synthesis in B16F10 cells," Pharmazie, vol. 63, no. 4, pp. 290-295, 2008.

[11] L. M. McCune and T. Johns, "Antioxidant activity in medicinal plants associated with the symptoms of diabetes mellitus used by the Indigenous Peoples of the North American boreal forest," Journal of Ethnopharmacology, vol. 82, no. 2-3, pp. 197-205, 2002.

[12] D. S. Kim, H. J. Cho, H. R. Choi, S. B. Kwon, and K. C. Park, "Isolation of human epidermal stem cells by adherence and the reconstruction of skin equivalents," Cellular and Molecular Life Sciences, vol. 61, no. 21, pp. 2774-2781, 2004.

[13] E. Bell, B. Ivarsson, and C. Merrill, "Production of a tissuelike structure by contraction of collagen lattices by human fibroblasts of different proliferative potential in vitro," Proceedings of the National Academy of Sciences of the United States of America, vol. 76, no. 3, pp. 1274-1278, 1979.

[14] M. W. Lee, Y. A. Lee, H. M. Park et al., "Antioxidative Phenolic Compounds from the Roots of Rhodiola sachalinensis A. Bor," Archives of Pharmacal Research, vol. 23, no. 5, pp. 455-458, 2000.

[15] A. Sonnenberg, J. Calafat, H. Janssen et al., "Integrin $\alpha 6 / \beta 4$ complex is located in hemidesmosomes, suggesting a major role in epidermal cell-basement membrane adhesion," Journal of Cell Biology, vol. 113, no. 4, pp. 907-917, 1991.

[16] R. Grose, C. Hutter, W. Bloch et al., "A crucial role of $\beta 1$ integrins for keratinocyte migration in vitro and during cutaneous wound repair," Development, vol. 129, no. 9, pp. 2303-2315, 2002.

[17] G. Pellegrini, E. Dellambra, O. Golisano et al., "p63 identifies keratinocyte stem cells," Proceedings of the National Academy of Sciences of the United States of America, vol. 98, no. 6, pp. 3156-3161, 2001.

[18] R. Bravo, R. Frank, P. A. Blundell, and H. Macdonald-Bravo, "Cyclin/PCNA is the auxiliary protein of DNA polymerase- $\delta$," Nature, vol. 326, no. 6112, pp. 515-517, 1987.

[19] B. Poljsak and R. Dahmane, "Free radicals and extrinsic skin aging," Dermatol Res Pract, vol. 2012, Article ID 135206, 4 pages, 2012.

[20] I. Paur et al., "Antioxidants in herbs and spices: roles in oxidative stress and redox signaling," in Herbal Medicine: Biomolecular and Clinical Aspects, I. F. F. Benzie and S. Wachtel-Galor, Eds., llc, Boca Raton, Fla, USA, 2011.

[21] H. Larjava, "Expression of $\beta 1$ integrins in normal human keratinocytes," American Journal of the Medical Sciences, vol. 301, no. 1, pp. 63-68, 1991.

[22] C. E. Klein, T. Steinmayer, J. M. Mattes, R. Kaufmann, and L. Weber, "Integrins of normal human epidermis: differential expression, synthesis and molecular structure," British Journal of Dermatology, vol. 123, no. 2, pp. 171-178, 1990.

[23] J. Labat-Robert and L. Robert, "Aging of the extracellular matrix and its pathology," Experimental Gerontology, vol. 23, no. 1, pp. 5-18, 1988.

[24] F. M. Watt and H. Fujiwara, "Cell-extracellular matrix interactions in normal and diseased skin," Cold Spring Harbor Perspectives in Biology, vol. 3, no. 4, 2011.
[25] D. K. Carroll, J. S. Carroll, C. O. Leong et al., "p63 regulates an adhesion programme and cell survival in epithelial cells," Nature Cell Biology, vol. 8, no. 6, pp. 551-561, 2006. 


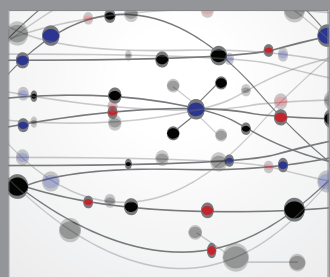

The Scientific World Journal
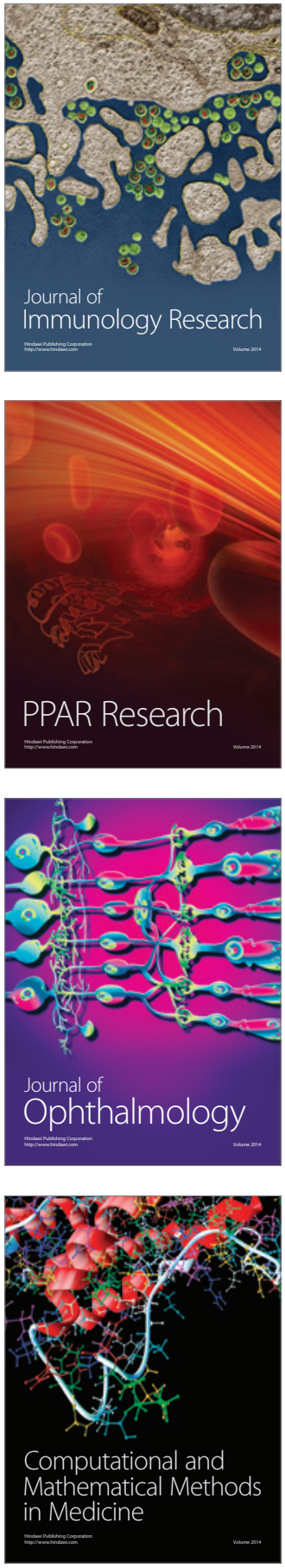

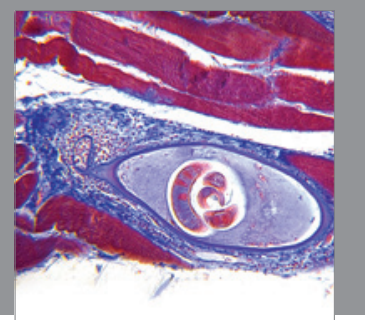

Gastroenterology

Research and Practice
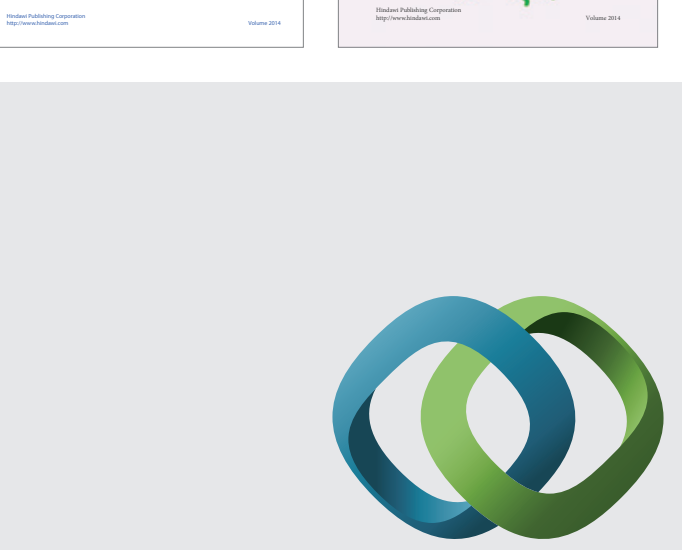

\section{Hindawi}

Submit your manuscripts at

http://www.hindawi.com
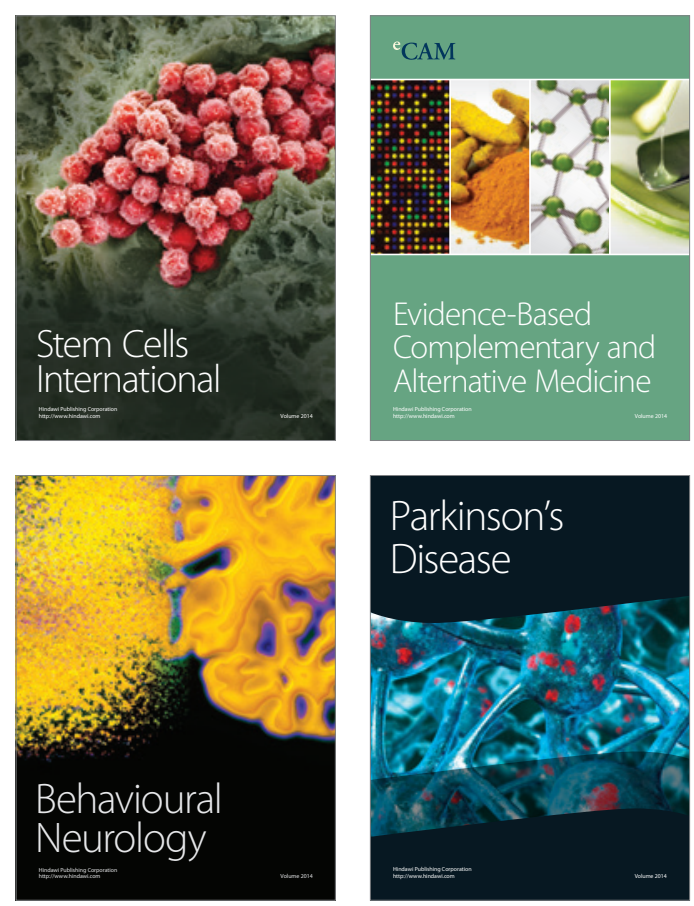

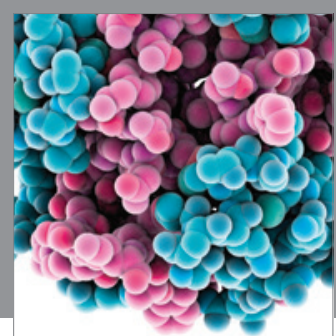

Journal of
Diabetes Research

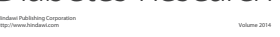

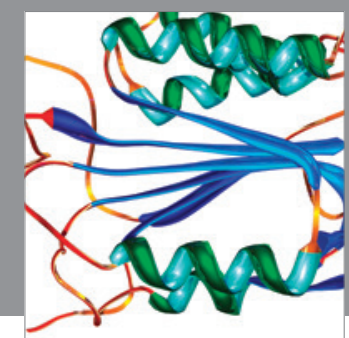

Disease Markers
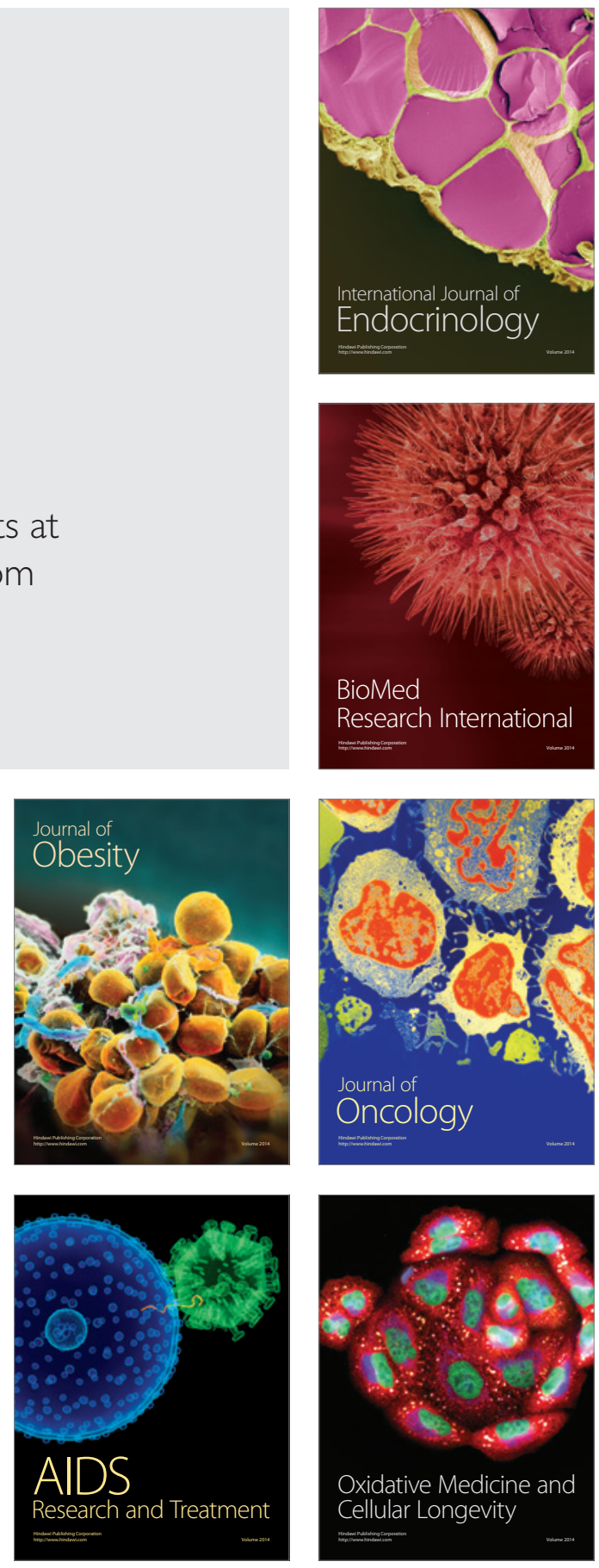